OESOPHAGUS

\title{
Effect of Helicobacter pylori eradication on treatment of gastro-oesophageal reflux disease: a double blind, placebo controlled, randomised trial
}

\author{
J C Y Wu, F K L Chan, J Y L Ching, W-K Leung, Y Hui, R Leong, S C S Chung, J J Y Sung
}

Gut 2004;53:174-179

See end of article for authors' affiliations

Correspondence to:

DrJ C Y Wu, Department of Medicine and Therapeutics, Prince of Wales Hospital, Shatin, Hong Kong; justinwu@ ekno.com

Accepted for publication 2 April 2003
Background: The role of Helicobacter pylori eradication in the management of gastro-oesophageal reflux disease (GORD) is controversial. We hypothesised that $H$ pylori eradication leads to worsened control of reflux disease.

Methods: Consecutive patients with weekly reflux symptoms were prospectively recruited for endoscopy and symptom evaluation. Patients were enrolled if they had $H$ pylori infection and required long term acid suppressants. Eligible patients were randomly assigned to omeprazole triple therapy (HpE group) or omeprazole with placebo antibiotics (Hp+ group) for one week. Omeprazole $20 \mathrm{mg}$ daily was given for eight weeks for healing of oesophagitis and symptom relief. This was followed by a maintenance dose of $10 \mathrm{mg}$ daily for up to 12 months. The primary study end point was the probability of treatment failure within 12 months, which was defined as either incomplete resolution of symptoms or oesophagitis at the initial treatment phase, or relapse of symptoms and oesophagitis during the maintenance phase. Predictors of treatment failure were determined by Cox's proportional hazards model.

Results: A total of 236 GORD patients were screened and 113 (47.9\%) were positive for H pylori; 104 (92\%) patients were included in the intention to treat analysis (53 in the $\mathrm{HpE}$ group and 51 in the $\mathrm{Hp}+$ group). Thirty one patients (30\%) had erosive oesophagitis at baseline. $\mathrm{H}$ pylori was eradicated in $98 \%$ of the $\mathrm{HpE}$ group and in $3.9 \%$ of the $\mathrm{Hp}+$ group. Overall, 15 patients $(28.3 \%)$ in the HpE group and eight patients (15.7\%) in the $\mathrm{Hp}+$ group had treatment failure. The 12 month probability of treatment failure was 43.2\% (95\% confidence interval (Cl) 29.9-56.5\%) in the $\mathrm{HpE}$ group and $21.1 \%(95 \% \mathrm{Cl} 9.9-32.3 \%)$ in the $\mathrm{Hp}+$ group (log rank test, $\mathrm{p}=0.043$ ). In the Cox proportional hazards model, after adjustment for the covariates age, sex, erosive oesophagitis, hiatus hernia, degree of gastritis, and severity of symptoms at baseline, $H$ pylori eradication was the only predictor of treatment failure ladjusted hazard ratio 2.47 (95\% Cl 1.05-5.85)).

Conclusion: $H$ pylori eradication leads to more resilient GORD.
$M$ ore than $70 \%$ of patients suffering from gastrooesophageal reflux disease (GORD) are dependent on long term use of acid suppressants. The Genval Workshop Report for GORD has confirmed the primary role of proton pump inhibitors (PPI) in the treatment of GORD and recommends that patients with non-erosive reflux disease and mild oesophagitis can be treated by stepdown dosing of PPI for maintenance therapy. ${ }^{12}$

The effects of Helicobacter pylori infection in patients with GORD has been vigorously debated in recent years. Most Asian epidemiological studies reported a lower prevalence of $H$ pylori infection among GORD patients ${ }^{3}{ }^{4}$ but this negative association is less prominent in Caucasian populations. As the protective role of $H$ pylori against GORD is attributed to suppressed gastric acid secretion in patients with gastritis, ${ }^{5}$ ethnic differences may be attributed to different patterns of $H$ pylori gastritis among these populations. The role of $H$ pylori in the treatment of GORD is also controversial. H pylori has been reported to augment the acid suppressive effect of PPI, which may contribute to more rapid healing of oesophagitis and better symptomatic relief in infected patients. ${ }^{6-8}$ However, this observation is not consistent. ${ }^{9}$ Interventional studies investigating the effect of $H$ pylori eradication on GORD also yielded conflicting results. In a recent randomised study, $H$ pylori eradication did not produce any effect on symptom relapse after therapy with PPI. ${ }^{10}$ Another smaller scale interventional study even showed that $H$ pylori eradication prolonged the disease free interval in GORD patients. ${ }^{11}$ However, we have previously reported that $H$ pylori eradication increased oesophageal acid exposure and aggravated oesophagitis in a subset of GORD patients. ${ }^{12}$ All of the aforementioned studies evaluated relapse of GORD after discontinuation of acid suppressive therapy. In clinical practice, however, very few GORD patients can be totally independent of medication. To date, none of the existing studies evaluated the clinical course of GORD in patients taking maintenance acid suppressants after $H$ pylori eradication.

The aim of this study was to evaluate the effect of $H$ pylori eradication on maintenance treatment of GORD. We hypothesised that $H$ pylori eradication results in more difficult control of disease in reflux patients eligible for stepdown management strategy.

\section{PATIENTS AND METHOD}

Patients and endoscopy

This was a 12 month, double blind, randomised, placebo controlled trial. From May 1999 to December 2000, consecutive patients presenting with weekly attacks of heartburn

\footnotetext{
Abbreviations: GORD, gastro-oesophageal reflux disease; PPI, proton pump inhibitors; NSAID, non-steroidal anti-inflammatory drugs; CagA, cytotoxin associated gene $\mathrm{A}$
} 
and/or acid regurgitation in the previous 12 months were recruited for symptom assessment and endoscopy. Patients were excluded if they had a current or past history of peptic ulcer disease, previous gastric surgery, pregnancy, severe complications of reflux disease such as stricture and Barrett's oesophagus, previously received anti-Helicobacter therapy, or used of non-steroidal anti-inflammatory drugs (NSAID) or PPI within four weeks before entry into the study. Upper endoscopy (Olympus XQ-200 or XQ-240 endoscope) was performed to exclude coexisting peptic ulcer and assess the severity of reflux oesophagitis using the modified Savary Miller grading system. ${ }^{13}$ In this study, grade 1 oesophagitis referred to the presence of single or isolated erosion(s) on one mucosal fold; grade 2, non-circumferential erosions on more than one mucosal fold with or without confluence; grade 3, circumferential erosions; and grade 4, the presence of stricture or ulcer. The presence of a hiatus hernia was also noted. Diagnosis of $H$ pylori infection was confirmed if both biopsy urease test and histology were positive. Two biopsy specimens were obtained from the antrum and corpus for histological assessment by a single pathologist who was blinded to the treatment groups. Neutrophil and mononuclear cell infiltration, intestinal metaplasia, and atrophy were graded (0-3) according to the updated Sydney classification. ${ }^{14}$ A combined inflammatory score (0-6), using the sum of neutrophil and mononuclear cell infiltration scores, was used to assess the severity of gastritis. Serum samples were collected for determination of cytotoxin associated gene A ( $\operatorname{Cag} A$ ) status (Helico Blot 2.0; Genelab, Singapore). The study was approved by clinical ethics committee of the Chinese University of Hong Kong. Written informed consents were obtained from all participants.

\section{Symptom assessment}

Reflux symptoms were evaluated using a structured questionnaire by face to face interview. Duration of symptoms was recorded. Severity of heartburn and acid regurgitation were rated using a four point Likert scale (0, asymptomatic; 1 , mild - only recall on questioning and not affecting daily activity; 2, moderate-constantly aware of the symptom but not affecting daily activity; 3, severe-interferes with daily activity). The higher symptom score was used if there was a discrepancy between the rating of heartburn and acid regurgitation.

\section{Randomisation}

After baseline assessment, eligible patients were randomly assigned to eradication therapy with omeprazole $20 \mathrm{mg}$, amoxycillin $\mathrm{l} \mathrm{g}$, and clarithromycin $500 \mathrm{mg}$ each given twice daily for one week ( $\mathrm{H} p \mathrm{E}$ group), or control therapy with omeprazole $20 \mathrm{mg}$ and identical looking placebo antibiotics each given twice daily for one week ( $H p+$ group). The random allocation sequence was obtained from a computer generated list of random numbers in blocks of 10. Concealed allocation was achieved by an independent staff member who assigned treatments according to consecutive numbers in sealed envelopes. Study medications were dispensed as sealed packages in consecutive numbers. Medication adherence was measured by pill counts during interval visits. All recruited patients, physicians, and research nurses were blinded to the treatment assigned throughout the whole study period.

\section{Initial phase}

After the first week's trial medication, patients from both groups were given eight weeks of omeprazole $20 \mathrm{mg}$ once daily. Symptoms were reviewed at the end of treatment. Global symptom assessment was conducted in addition to individual symptom scores. This was a binary outcome measure in which patients were asked to give either a positive or negative response to the question "do you have poor overall reflux symptom control with the present treatment that requires a more potent regimen?" Follow up endoscopy was arranged for patients with erosive oesophagitis to assess healing. Patients with incomplete healing of oesophagitis or persistent symptoms were regarded as treatment failures.

\section{Maintenance phase}

Patients with complete resolution of symptoms and oesophagitis were given omeprazole $10 \mathrm{mg}$ once daily as maintenance therapy until the end of 12 months. Follow up visits were arranged at 4, 6, 9, and 12 months for symptom evaluation and drug compliance. Endoscopic examination, including biopsies for histological evaluation and biopsy urease test, was offered when reflux symptom recurred or at the end of 12 months. Omeprazole was stopped after 12 months and patients underwent a ${ }^{13} \mathrm{C}$ urea breath test four weeks after cessation of omeprazole to determine $H$ pylori status (fig 1).

\section{End points}

The primary end point was treatment failure within 12 months, which was defined as either incomplete resolution of symptoms or oesophagitis at the initial treatment phase, or relapse of symptoms and/or oesophagitis during the maintenance phase. Symptom deterioration was assessed by the global symptom assessment. Endoscopic relapse was defined as recurrence of erosive oesophagitis (that is, Savary Miller grade 1 or above) in the maintenance phase. The secondary end point was reflux symptom score at the last follow up.

\section{Statistical analysis}

We anticipated that $45 \%$ of patients receiving $H$ pylori eradication therapy would have treatment failure during the 12 month period..$^{15}$ To detect a $25 \%$ difference in treatment failure rate, a total of $103 \mathrm{H}$ pylori positive GORD patients were required to achieve $80 \%$ power at the $5 \%$ significance level (PASS software, NCSS). The Kaplan-Meier method was used to estimate the likelihood of reaching the

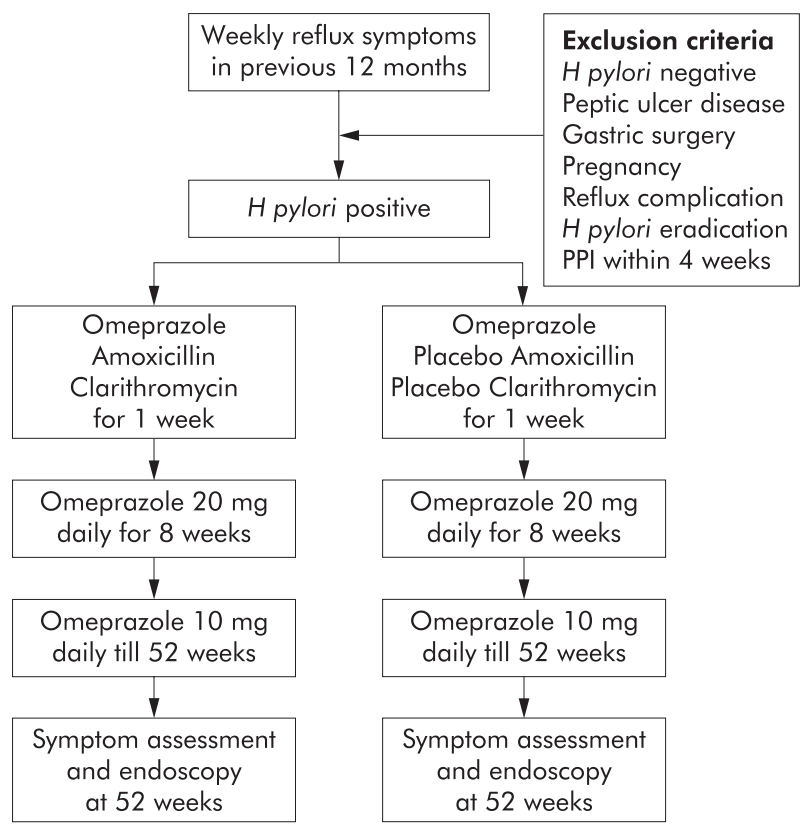

Figure 1 Algorithm for the study design. 


\begin{tabular}{|c|c|c|c|}
\hline Characteristic & $\begin{array}{l}\text { Eradication } \\
\text { (Group HpE) } \\
(\mathrm{n}=53)\end{array}$ & $\begin{array}{l}\text { Placebo } \\
\text { (Group } \mathrm{Hp+l} \\
(\mathrm{n}=51)\end{array}$ & p Value \\
\hline Age $(y)^{*}$ & $54.0(13.8)$ & $53.0(14.9)$ & 0.81 \\
\hline Male (\%) & $26(49.1)$ & $23(45.1)$ & 0.69 \\
\hline Current cigarette use (\%) & 7 (13.2) & $10(19.6)$ & 0.38 \\
\hline Alcohol consumption (\%) & $10(18.9)$ & $10(19.6)$ & 0.92 \\
\hline Body mass index* & $24.7(3.8)$ & $23.4(3.4)$ & 0.7 \\
\hline \multicolumn{4}{|c|}{ Grading of oesophagitis (\%) (modified Savary Miller) } \\
\hline 0 & $38(71.7)$ & $35(68.6)$ & \\
\hline $1-2$ & $14(26.4)$ & $14(27.5)$ & 0.81 \\
\hline $3-4$ & $1(1.9)$ & $2(3.9)$ & \\
\hline Hiatus hernia (\%) & $10(18.9)$ & $9(17.6)$ & 0.87 \\
\hline Prevalence of CagA positivity (\%) & 70 & 75 & 0.59 \\
\hline Previous use of proton pump inhibitor (\%) & $3(5.7)$ & $2(3.9)$ & 1.0 \\
\hline \multicolumn{4}{|l|}{ Symptom score (\%) } \\
\hline 1 & $15(28.3)$ & $20(39.2)$ & \\
\hline 2 & $29(54.7)$ & $28(54.9)$ & 0.10 \\
\hline 3 & 9 (17) & $3(5.9)$ & \\
\hline \multicolumn{4}{|l|}{ Symptom duration (\%) } \\
\hline 1 y & $17(32.1)$ & $22(43.1)$ & \\
\hline$>1-5 y$ & $23(43.4)$ & 16 (31.4) & 0.57 \\
\hline$>5-10 y$ & $5(9.4)$ & $4(7.8)$ & \\
\hline$>10 y$ & $8(15.1)$ & $9(17.6)$ & \\
\hline
\end{tabular}

end point of treatment failure within 12 months, according to the intention to treat principle. The log rank test was used for comparisons between treatment groups. Patients who withdrew due to events other than treatment failure were analysed up to the last follow up visit. Failure to take at least $75 \%$ of the study drugs was considered a protocol violation. Patient baseline characteristics were compared using the Student's $t$ test for parametric data, the Mann-Whitney U test for non-parametric data, and Pearson's $\chi^{2}$ test for proportions (SPSS software, version 10.0; SPSS, Chicago, Illinois, USA). A Cox's proportional hazards model was used to adjust for confounding covariates including, age, sex, erosive oesophagitis (presence or absence), hiatus hernia (presence or absence), gastritis (0-2 mild; 3-4 moderate; 5-6 severe), duration ( 1 year, $>1-5$ years, $>5-10$ years, $>10$ years) and severity (0-4) of symptoms at baseline. Histological changes

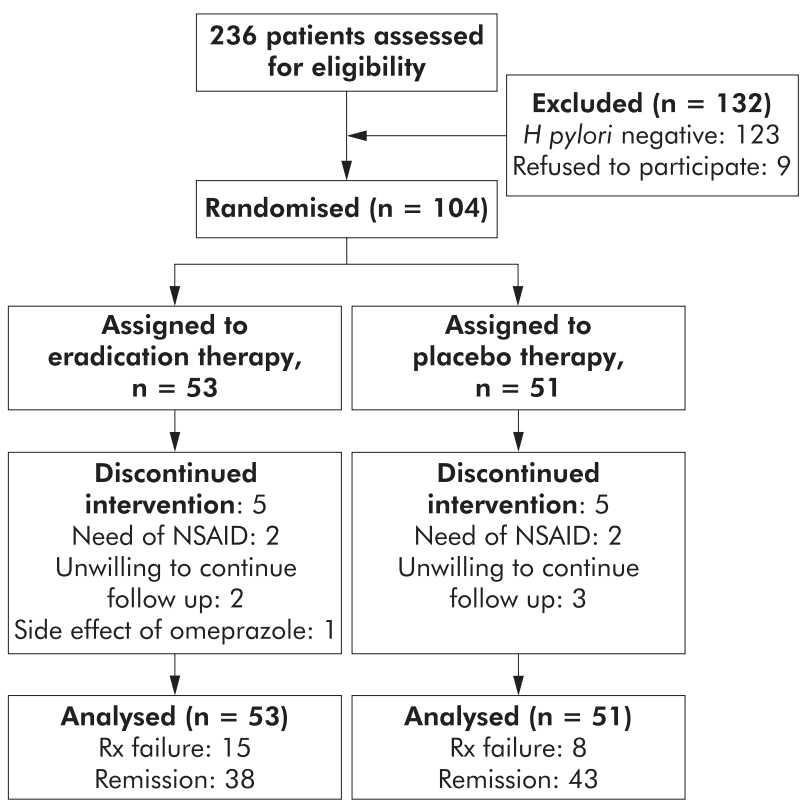

Figure 2 Outcome of the recruited patients. NSAID, non-steroidal antiinflammatory drugs. before and after treatment were compared using the Wilcoxon signed rank test for paired samples within treatment groups and the Mann-Whitney $\mathrm{U}$ test between groups, respectively. A two tailed $\mathrm{p}$ value of less than 0.05 was taken to indicate statistical significance.

\section{RESULTS}

A total of 236 consecutive patients with GORD were screened. Among them, 113 patients $(47.9 \%)$ were infected with $H$ pylori. Nine patients refused to participate and $104 \mathrm{H}$ pylori infected patients were recruited into the study (fig 2). Seventy one patients had a CagA serology test performed, and the prevalence of the CagA positive strain in $\mathrm{HpE}$ and $\mathrm{Hp}+$ patients was $70 \%$ and $74 \%$, respectively. Fifty three patients were randomly assigned to receive eradication therapy ( $H p \mathrm{E}$ ) and 51 to receive placebo $(H p+)$. The two groups were comparable in age, sex, body mass index, baseline gastritis, prevalence of hiatus hernia, and severity of reflux symptom (table 1). H pylori eradication was successful in 98\% (52/53) in the $H p \mathrm{E}$ group according to the ${ }^{13} \mathrm{C}$ urea breath test at 12 months. Two $(3.9 \%)$ patients in the $H p+$ group had negative $H$ pylori status at the end of the study. In the $H p \mathrm{E}$ group, five patients discontinued the study medications

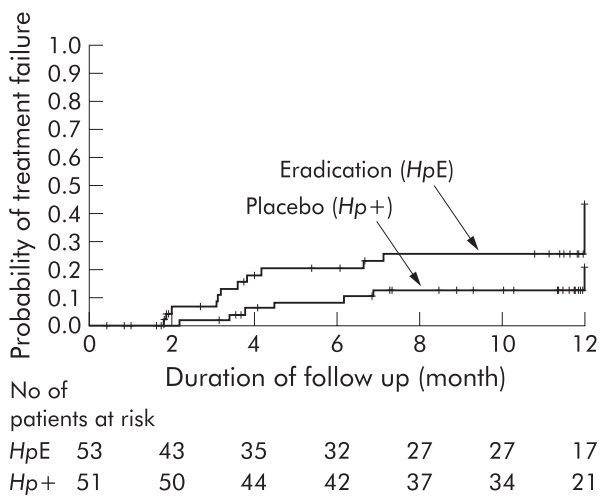

Figure 3 Kaplan-Meier curves showing the cumulative proportion of patients with treatment failure in the eradication group ( $\mathrm{HpE}$ group) and the control group (Hp+ group). ${ }^{*} p<0.043, \log$ rank test. 


\begin{tabular}{|c|c|c|c|}
\hline $\begin{array}{l}\text { Histological grading (updated Sydney } \\
\text { classification) }\end{array}$ & $\begin{array}{l}\text { Eradication (Group HpE) } \\
(n=53)\end{array}$ & $\begin{array}{l}\text { Placebo (Group Hp+) } \\
(\mathrm{n}=51 \text { ) }\end{array}$ & p Value \\
\hline \multicolumn{4}{|l|}{ Antral gastritis (\%) } \\
\hline $0-2$ & $5(9.6)$ & $11(22)$ & \multirow{3}{*}{0.19} \\
\hline $3-4$ & $32(61.5)$ & $24(48)$ & \\
\hline $5-6$ & $15(28.8)$ & $15(30)$ & \\
\hline \multicolumn{4}{|l|}{ Corpus gastritis (\%) } \\
\hline $0-2$ & $25(49)$ & $22(44.9)$ & \multirow{3}{*}{0.67} \\
\hline $3-4$ & $19(37.3)$ & $17(34.7)$ & \\
\hline $5-6$ & $7(13.7)$ & $10(20.4)$ & \\
\hline \multicolumn{4}{|l|}{ Antral atrophy (\%) } \\
\hline 0 & $46(88.5)$ & $40(80)$ & \multirow{4}{*}{0.53} \\
\hline 1 & $4(7.7)$ & 7 (14) & \\
\hline 2 & $2(3.8)$ & $2(4)$ & \\
\hline 3 & $0(0)$ & $1(2)$ & \\
\hline \multicolumn{4}{|l|}{ Corpus atrophy (\%) } \\
\hline 0 & $50(98)$ & $47(95.9)$ & \multirow{4}{*}{0.49} \\
\hline 1 & $1(2)$ & $2(4.1)$ & \\
\hline 2 & $0(0)$ & $0(0)$ & \\
\hline 3 & $0(0)$ & $0(0)$ & \\
\hline \multicolumn{4}{|l|}{ Antral intestinal metaplasia (\%) } \\
\hline 0 & $38(73.1)$ & $36(72)$ & \multirow{4}{*}{0.78} \\
\hline 1 & $8(15.4)$ & $8(16)$ & \\
\hline 2 & $6(11.5)$ & $5(10)$ & \\
\hline 3 & $0(0)$ & $1(2)$ & \\
\hline \multicolumn{4}{|l|}{ Corpus intestinal metaplasia (\%) } \\
\hline 0 & $47(92.2)$ & $48(98)$ & \multirow{4}{*}{0.32} \\
\hline 1 & $2(3.9)$ & $1(2)$ & \\
\hline 2 & $2(3.9)$ & $0(0)$ & \\
\hline 3 & $0(0)$ & $0(0)$ & \\
\hline
\end{tabular}

because of side effects of omeprazole $(\mathrm{n}=1)$, need for NSAID $(n=2)$, or unwilling to continue follow up $(n=2)$. There were also five $\mathrm{H} p+$ patients who discontinued medications for concomitant NSAID use $(\mathrm{n}=2)$ and unwilling to continue follow up. All study patients achieved compliance of more than $80 \%$ with study medications (fig 2 ).

In the $H p \mathrm{E}$ group, 15 patients experienced treatment failure (five in the initial phase and 10 in the maintenance phase) (figs 2, 3). Four patients in the initial phase had incomplete symptom resolution and one had persistent oesophagitis. Of the 10 patients with symptom relapse in the maintenance phase, four had both symptom and endoscopic relapse. In the $\mathrm{Hp}+$ group, eight patients experienced treatment failure (none at the initial phase and eight in the maintenance phase) with symptom relapse but none had relapse of oesophagitis. The 12 month probability of treatment failure was $43.2 \%$ (95\% confidence interval (CI) 29.9-56.5\%) in the $H p \mathrm{E}$ group and $21.1 \%$ (95\% CI 9.9-32.3\%) in the $H p+$ group (log rank test, $\mathrm{p}=0.043) . H p+$ patients also had a lower reflux symptom score (median score 0 ; range $0-1$ ) than $H p$ E patients (median score 1 ; range $0-2$ ) at the last visit (Mann Whitney $\mathrm{U}$ test, $\mathrm{p}=0.02$ ).

\begin{tabular}{|c|c|c|c|}
\hline & Eradication (Group HpE)* & Placebo (Group $\mathrm{Hp}+$ )t & p Value \\
\hline \multicolumn{4}{|l|}{ Antral gastritis } \\
\hline Baseline & $4(1-6)$ & $4(1-6)$ & 0.28 \\
\hline End of treatment & $1(0-4)$ & $3(1-6)$ & $<0.0001$ \\
\hline \multicolumn{4}{|l|}{ Corpus gastritis } \\
\hline Baseline & $3(0-6)$ & $3(0-6)$ & 0.56 \\
\hline End of treatment & $1(0-4)$ & $4(0-6)$ & $<0.0001$ \\
\hline \multicolumn{4}{|l|}{ Antral atrophy } \\
\hline Baseline & $0(0-2)$ & $0(0-3)$ & 0.24 \\
\hline End of treatment & $0(0-3)$ & $0(0-3)$ & 0.63 \\
\hline \multicolumn{4}{|l|}{ Corpus atrophy } \\
\hline Baseline & $0(0-1)$ & $0(0-1)$ & 0.54 \\
\hline End of treatment & $0(0-1)$ & $0(0-1)$ & 0.85 \\
\hline \multicolumn{4}{|c|}{ Antral intestinal metaplasia } \\
\hline Baseline & $0(0-2)$ & $0(0-3)$ & 0.88 \\
\hline End of treatment & $0(0-3)$ & $0(0-3)$ & 0.91 \\
\hline \multicolumn{4}{|c|}{ Corpus intestinal metaplasia } \\
\hline Baseline & $0(0-2)$ & $0(0-1)$ & 0.18 \\
\hline End of treatment & $0(0-1)$ & $0(0-1)$ & 0.45 \\
\hline \multicolumn{4}{|c|}{$\begin{array}{l}\text { All values are median (range). } \\
\text { *Within HpE group comparison between baseline and end of treatment: antral gastritis: } p<0.0001 \text {, suggesting } \\
\text { significant resolution of gastritis after } H \text { pylori eradication; corpus gastritis: } p<0.0001 \text {, suggesting significant } \\
\text { resolution of gastritis after } H \text { pylori eradication; antral atrophy: } p=0.07 \text {; corpus atrophy: } p=0.32 \text {; antral intestinal } \\
\text { metaplasia: } p=0.11 \text {; corpus intestinal metaplasia: } p=1.0 \text {. } \\
\text { †Within } H p+\text { group comparison between baseline and end of treatment: antral gastritis: } p=0.15 \text {; corpus gastritis: } \\
p<0.0001 \text {, suggesting significant increase in severity of gastritis; antral atrophy: } p=0.28 ; \text { corpus atrophy: } 0.32 \text {; } \\
\text { antral intestinal metaplasia: } p=0.053 \text {; corpus intestinal metaplasia: } p=0.32 \text {. }\end{array}$} \\
\hline
\end{tabular}


Both treatment groups had similar degrees of gastritis at baseline. The majority of patients had antral predominant gastritis on entry into study but over half also had moderate to severe corpus gastritis (table 2). In the $H p \mathrm{E}$ group, there was a significant reduction in the severity of gastritis at both the antrum and corpus after $H$ pylori eradication $(\mathrm{p}<0.0001)$ (table 3 ). In contrast, in the $H p+$ group, there was a change in the pattern of gastritis from antral predominant to corpus predominant gastritis. While severity of gastritis at the antrum was unaltered $(p=0.15)$, gastritis scores at the corpus significantly increased after one year of PPI therapy $(p<0.0001)$. Both groups of patients had comparable degrees of gastric atrophy and intestinal metaplasia (table 2). There was no significant change in these two histological conditions at the end of 12 months in both the $\mathrm{HpE}$ and $\mathrm{Hp}+$ groups (table 3 ).

In the Cox proportional hazards model, $H$ pylori eradication was identified as the only factor associated with treatment failure. The unadjusted odds ratio of $H$ pylori eradication was 2.34 (95\% CI 1.0-5.53). After adjustment for the confounding covariates, the adjusted hazard ratio was 2.47 (95\% CI 1.05$5.85)$. There was no significant difference in treatment failure between patients with endoscopy negative disease and erosive oesophagitis $\left(22.3 \% \vee 30.3 \% ; \mathrm{p}=0.10, \chi^{2}\right.$ test $)$.

The effect of baseline corpus gastritis on treatment failure in $H p \mathrm{E}$ patients was evaluated in subgroup analysis. Eight of 26 patients $(30.8 \%)$ with moderate or severe gastritis developed treatment failure compared with seven of 25 $(28 \%)$ in patients with mild gastritis. There was no significant difference in treatment failure rate between the two subgroup of patients $\left(p=0.31, \chi^{2}\right.$ test).

\section{DISCUSSION}

The impact of antibacterial therapy on the severity of GORD has been a subject of heated debate. Tefera et al found no difference in oesophageal acid exposure or reflux symptoms in GORD patients 12 weeks after $H$ pylori eradication. ${ }^{17}$ Moayyedi et al also reported that $H$ pylori eradication had no deleterious effect on symptomatic relapse among GORD patients. ${ }^{10}$ Schwizer et al observed an earlier relapse for GORD patients with persistent $H$ pylori infection compared with those who received eradication therapy, although both oesophageal acid exposure and gastric acidity were unaltered. ${ }^{11}$ In contrast, our group has previously reported exacerbation of oesophageal acid exposure and disease severity in a subset of GORD patients after antibacterial therapy. ${ }^{12}$ The discrepancy is probably due to different study designs, such as inclusion criteria and timing of follow up investigations, and ethnic differences in the pattern of $H$ pylori gastritis.

In the present study, we set out to evaluate the effect of $H$ pylori eradication on disease severity in GORD patients receiving maintenance acid suppressive therapy. Patients recruited had relatively mild reflux disease, representing patients in primary and secondary care. Furthermore, the prevalence of hiatus hernia was relatively low compared with GORD patients in Western populations. This finding is consistent with the previously reported prevalence in Chinese patients. ${ }^{18}{ }^{19}$ Unlike previous studies, we introduced a "stepdown" maintenance therapy after successful initial full dose PPI therapy. This design was based on the Genval Workshop's recommendation for mild and moderate reflux disease, in which over $70 \%$ of patients required maintenance medical treatment. ${ }^{2}$ Due to the lack of universally accepted and validated symptom scores for GORD, we used global symptom assessment instead of symptom scores as the primary measure of treatment response. ${ }^{20}$ As unequal proportions of high risk patients may develop treatment failure during the initial phase between the two groups, this may result in the phenomenon of "elimination of susceptibles". To avoid comparison of the two groups with unmatched treatment failure risks in the maintenance phase, we predefined a composite end point that included treatment failures in both the initial and maintenance phases. In contrast with previous studies, our results showed that eradication of $H$ pylori caused an increased risk of treatment failure of GORD. The similar treatment failure rates in the two groups during the maintenance phase can be attributed to the lower risk of $H p \mathrm{E}$ patients who remained in the maintenance phase compared with the $\mathrm{Hp}+$ group. After adjusting for other confounding factors, $H$ pylori eradication was the only predictive factor for failure using the stepdown strategy of the Genval Workshop.

There are several possible explanations for worsening control of reflux disease after $H$ pylori eradication. Firstly, persistent $H$ pylori infection generates ammonia which augments the acid suppressing effect of medication. ${ }^{621}$ More importantly, acid suppressive therapy intensifies corpus gastritis and hence further suppresses acid secretion in the stomach. ${ }^{22} 23$ Secondly, early rebound of gastric acid hypersecretion has been observed after cessation of PPI. This phenomenon can be alleviated in patients with $H$ pylori infection. ${ }^{24}$ In patients with successful eradication of $H$ pylori, rebound acid secretion on reduced dosage of PPI may cause relapse of GORD. Finally, $H$ pylori eradication may increase oesophageal acid exposure in a subset of patients without maintenance acid suppressive therapy, ${ }^{12}$ probably due to resolution of corpus gastritis and recovery of gastric acid secretion. $^{52526}$ Recovery of gastric acid secretion after resolution of corpus gastritis counteracts the therapeutic effect of maintenance acid suppressive therapy. It is noteworthy that the majority of recruited patients in this study were infected by the CagA positive strain of $H$ pylori. Over half of these patients had moderate or severe corpus gastritis, which reflects the fact that corpus gastritis is generally more predominant in the Chinese population. Hence a high proportion of study patients were susceptible to increased acid secretion with resolution of gastritis. We suggest that in populations where CagA positive $H$ pylori is prevalent, more GORD patients have corpus predominant gastritis and develop worsened control of reflux disease because of recovered gastric acid secretion in a significant subset of patients. This postulation is supported by a recent study from Greece which showed that patients infected with the cagA positive strain of $H$ pylori were at risk of developing oesophagitis after eradication therapy.27

The impact of long term PPI therapy on H pylori gastritis is another subject of dispute. Kuipers et al reported in his cohort that $H$ pylori infected patients receiving long term PPI had progression of atrophic gastritis compared with patients who received antireflux surgery. ${ }^{28}$ Although this profound difference in histological changes was not substantiated in a subsequent randomised trial, ${ }^{29}$ the anxiety was not entirely relieved. In a recent randomised study revisiting this issue, Kuipers et al reported that corpus gastritis in GORD patients progressed on long term omeprazole treatment if $H$ pylori had not been eradicated, and there was reversal of gastritis in those randomised to $H$ pylori eradication. ${ }^{30}$ Therefore, in the Second Maastricht's Consensus, it was recommended that before prescribing long term PPI for GORD, $H$ pylori eradication is indicated in order to prevent progression of atrophic gastritis and intestinal metaplasia. ${ }^{31}$ In our study, intestinal metaplasia and gastric atrophy were relatively uncommon and there was no significant progression due to the short duration of follow up. Yet, patients with persistent infection have intensified inflammation after one year of half dose omeprazole therapy. Progression of histology along Correa's cascade of gastric carcinogenesis would be a 
concern, particularly in populations with a high incidence of gastric cancer.

The data from this study are somewhat limited by the relatively small sample size. As we demonstrated in our previous study that patients with GORD are less likely to be infected with $H$ pylori, ${ }^{3}$ we encountered substantial difficulties in recruiting patients with frequent GORD symptoms for this study. A larger sample size would allow us to perform subgroup analysis on patients receiving anti-Helicobacter therapy to predict who are likely to relapse on low dose PPI therapy.

In conclusion, our study showed that $H$ pylori eradication rendered more difficult control of reflux disease. However, balancing the risk of gastric carcinogenesis and peptic ulcer formation against the need for higher doses of acid suppressive therapy for symptom control, we would recommend $H$ pylori eradication before long term PPI therapy.

\section{ACKNOWLEDGEMENTS}

This work was supported by a direct grant from the Chinese University of Hong Kong (No 2040842) and research grants from the Hong Kong Society of Gastroenterology and AstraZeneca Hong Kong Limited. We are indebted to Professor John Dent for advice on manuscript writing; YK Luk, MD, MS Lai, MD, and Nelson NS Kung, $\mathrm{MD}$, for assistance with patient recruitment; KF To, MD, and CL Choi, MD, for assistance with histological assessment; and Miss Carrian Cheung, RN, for data acquisition.

\section{Authors' affiliations}

J C Y Wu, F K L Chan, J Y L Ching, W-K Leung, Y Hui, R Leong,

S C S Chung, J J Y Sung, Department of Medicine and Therapeutics, Prince of Wales Hospital, the Chinese University of Hong Kong, Hong Kong

\section{REFERENCES}

1 Vigneri S, Termini R, Leandro $G$, et al. A comparison of five maintenance therapies for reflux oesophagitis. N Engl J Med 1995;333:1 106-10.

2 Dent J, Brun J, Fendrick AM, et al. An evidence-based appraisal of reflux disease management-the Genval Workshop Report. Gut 1999;44(suppl 2):S1-16.

3 Wu JCY, Sung JY, Ng EK, et al. Prevalence and distribution of $\mathrm{H}$. pylori in gastro-oesophageal reflux disease: a study from the East. Am J Gastroenterol 1999:94:1790-4

4 O'Connor HJ. Helicobacter pylori and gastro-oesophageal reflux diseaseclinical implications and management. Aliment Pharmacol Ther 1999;13:117-27.

5 El Omar EM, Oien K, el Nujumi A, et al. Helicobacter pylori infection and chronic gastric acid hyposecretion. Gastroenterology 1997;113:15-24.

6 Verdu EF, Armstrong D, Fraser R, et al. Effect of Helicobacter pylori status on intragastric $\mathrm{pH}$ during treatment with omeprazole. Gut 1995;36:539-43.

7 Holtmann G, Cain C, Malfertheiner P. Gastric Helicobacter pylori infection accelerates healing of reflux esophagitis during treatment with the proton pump inhibitor pantoprazole. Gastroenterology 1999;117:11-16.

8 Verdu EF, Armstrong D, Idstrom JP, et al. Effect of curing Helicobacter pylori infection on intragastric $\mathrm{pH}$ during treatment with omeprazole. Gut 1995; 37:743-8.

9 Adamek RJ, Behrendt J, Wenzel C. Relapse and prevention in reflux oesophagitis with regard to Helicobacter pylori status: a double-blinded, randomized, multicentre trial to compare the efficacy of pantoprazole versus ranitidine. Eur J Gastroenterol Hepatol 2001;13:811-17.

10 Moayyedi P, Bardhan C, Young L, et al. Helicobacter pylori eradication does not exacerbate reflux symptoms in gastroesophageal reflux disease. Gastroenterology 2001;121:1120-6.

11 Schwizer W, Thumshirn M, Dent J, et al. Helicobacter pylori and symptomatic relapse of gastro-oesophageal reflux disease: a randomised controlled trial. Lancet 2001;357:1738-42.

12 Wu JCY, Chan FKL, Wong SKH, et al. Effect of Helicobacter pylori eradication on oesophageal acid exposure in patients with reflux oesophagitis. Aliment Pharmacol Ther 2002;16:545-52.

13 Armstrong D. Endoscopic evaluation of gastro-esophageal reflux disease. Yale J Biol Med 1999;72:93-100.

14 Dixon MF, Genta RM, Yardley JH, et al. Classification and grading of gastritis. The updated Sydney system. International Workshop on the Histopathology of Gastritis, Houston 1994. Am J Surg Pathol 1996;10:1161-81.

15 Bardhan KD, Cherian P, Vaishnavi A, et al. Erosive oesophagitis: outcome of repeated long term maintenance treatment with low dose omeprazole $10 \mathrm{mg}$ or placebo. Gut 1998;43:458-64.

16 Bate CM, Green JR, Axon AT, et al. Omeprazole is more effective than cimetidine in the prevention of recurrence of GORD-associated heartburn and the occurrence of underlying oesophagitis. Aliment Pharmacol Ther 1998; 12:41-7.

17 Tefera S, Hatlebakk JG, Berstad A. The effect of Helicobacter pylori eradication on gastro-oesophageal reflux. Aliment Pharmacol Ther 1999; 13:915-20.

18 Yeh C, Hsu CT, Ho AS, et al. Erosive esophagitis and Barrett's esophagus in Taiwan-A higher frequency than expected. Dig Dis Sci 1997;42:702-6.

19 Chang CS, Poon SK, Lien HC, et al. The incidence of reflux esophagitis among the Chinese. Am J Gastroenterol 1997;92:668-71.

20 Whitehead WE, Corazziari E, Prizont R, et al. Definition of a responder in clinical trials for functional gastrointestinal disorders: report on a symposium. Gut 1999;45(suppl 2):॥178-9.

21 Bercik P, Verdu EF, Armstrong D, et al. The effect of ammonia on omeprazoleinduced' reduction of gastric acidity in subjects with Helicobacter pylori infection. Am J Gastroenterol 2000;95:947-55.

22 Moayyedi P, Wason C, Peacock R, et al. Changing patterns of Helicobacter pylori gastritis in long-standing acid suppression. Helicobacter 2000;5:206-14.

23 Gillen D, Wirz AA, Neithercut WD, et al. Helicobacter pylori infection potentiates the inhibition of gastric acid secretion by omeprazole. Gut 1999;44:468-75.

24 Gillen D, Wirz AA, Ardill JE, et al. Rebound hypersecretion after omeprazole and its relation to on-treatment acid suppression and Helicobacter pylori status. Gastroenterology 1999;116:239-47.

25 Koike T, Ohara S, Sekine H, et al. Helicobacter pylori infection inhibits reflux esophagitis by inducing atrophic gastritis. Am J Gastroenterol 1999:94:3468-72.

26 Labenz J, Blum AL, Bayerdorffer E, et al. Curing Helicobacter pylori infection in patients with duodenal ulcer may provoke reflux esophagitis. Gastroenterology 1997; 112:1442-7.

27 Rokkas T, Ladas S, Triantafyllou K, et al. The association between CagA status and the development of esophagitis after the eradication of Helicobacter pylori. Am J Med 2001;110:703-7.

28 Kuipers EJ, Lundell L, Klinkenberg-Knol EC, et al. Atrophic gastritis and Helicobacter pylori infection in patients with reflux esophagitis treated with omeprazole or fundoplication. N Engl J Med 1996;334:1018-22.

29 Lundell L, Miettinen P, Myrvold HE, et al. Lack of effect of acid suppression therapy on gastric atrophy. Nordic Gerd Study Group. Gastroenterology 1999; 117:319-26.

30 Kuipers EJ, Nelis GF, Klinkenberg-Knol EC, et al. Helicobacter eradication for the prevention of atrophic gastritis during omeprazole therapy; a prospective randomized trial. Gastroenterology 2001;120(suppl 1):A14.

31 Malfertheiner P, Megraud F, O'Morain C, et al. Current concepts in the management of Helicobacter pylori infection -the Maastricht 2-2000 Consensus Report. Aliment Pharmacol Ther 2002;16:167-80. 